\title{
CASO CLÍNICO: ¿QUÉ PUEDE EXISTIR TRAS UNA FUNCIONALIDAD APARENTE? CASE REPORT: WHAT CAN EXIST AFTER APPARENT FUNCTIONALITY?
}

\author{
Susana Peñas-Cuesta ${ }^{a}$ e Irene de la Vega ${ }^{b}$ \\ a Psicóloga clínica. Centro de Salud Mental de Villalba. Comunidad de Madrid. \\ b Psicóloga clínica. Hospital de Día de Trastornos de Personalidad. Hospital Clínico San Carlos, Madrid. \\ irenevr@hotmail.com
}

Cómo referenciar este artículo/How to reference this article:

Peñas-Cuesta, S. y De la Vega, I. (2013). ¿Qué puede existir tras una funcionalidad aparente? [Case report: what can exist after apparent functionality?]. Acción Psicológica, 10(1), 109-114. http://dx.doi. org/10.5944/ap.10.1.7038

\section{Resumen}

El trastorno límite de la personalidad (TLP) es un trastorno grave consistente en un patrón general de impulsividad e inestabilidad en las relaciones, la autoimagen y los afectos, que suele requerir tratamiento intensivo, multidisciplinar y de larga duración. Se presenta un caso clínico en el que se realiza este tipo de abordaje en una paciente de 30 años con TLP y trastorno dismórfico corporal en el que predominan comportamientos impulsivos y potencialmente dañinos.

Palabras clave: Trastorno límite de la personalidad; Trastorno dismórfico corporal; tratamiento.

\footnotetext{
Abstract

The borderline personality disorder (BPD) is a severe disorder consisting of a general pattern of impulsivity and instability in relationships, self-image and emotions which often require
}

intensive, multidisciplinary and long lasting treatment. We present a clinical case with this type of approach, a 30 year old patient with BPD and body dysmorphic disorder with predominant impulsive and potentially harmful behaviors.

Keywords: borderline personality disorder; body dysmorphic disorder; treatment.

\section{Encuadre teórico}

El Trastorno límite de la personalidad es un trastorno grave, de curso crónico e inicio en la adolescencia, caracterizado por un patrón general de inestabilidad en las relaciones afectivas, la autoimagen y la afectividad y una notable impulsividad. Es característico de estos pacientes el miedo intenso al abandono, relaciones inestables y caóticas, comportamientos impulsivos y autodestructivos, crisis suicidas, manifestaciones extremas de ira, sentimientos de vacío y falta de identidad y episodios micropsicóticos o de despersonalización en los 
momentos de estrés (DSM IV TR; APA, 2000.). Es muy frecuente, además, la comorbilidad con trastornos del Eje I, lo que hace a este grupo de pacientes especialmente heterogéneo y grave. Además, el nivel de deterioro social y funcional suele ser notable y la adherencia al tratamiento escasa. Según Gunderson y Links (2009), para el tratamiento de los pacientes es necesaria una modificación de los sistemas de intervención tradicionales. Los pacientes con TLP pueden beneficiarse de hospitalizaciones cortas pero, al alta, suelen requerir niveles de apoyo y estructura mayores que los ofrecidos por un seguimiento ambulatorio. El tratamiento ambulatorio intensivo está indicado para aquellos pacientes que cuentan con un mínimo de funcionamiento social y tienen un lugar adecuado para vivir. En este nivel se administran terapias específicas para el TLP durante más de cinco horas a la semana, proporciona estructura y apoyo y mejora la adaptación social y el control impulsivo de pacientes graves pero capaces de cierto grado de autonomía.

\section{Descripción del sujeto}

RB es una mujer de 30 años que acude derivada desde la red privada tras un ingreso hospitalario por síntomas ansioso-depresivos de difícil contención ambulatoria.

\section{Antecedentes personales}

A los ocho años acude a psicólogo infantil por ansiedad y alteraciones de conducta tras un accidente de coche. Sin otro contacto con salud mental hasta los veinte años, momento en el que acude a un psiquiatra que diagnostica síndrome ansioso depresivo y onicofagia y trata con Sertralina. Acude a tratamiento psicológico desde hace tres años, por sintomatología depresiva y obsesiva, pero de forma inconstante, abandonando muchos profesionales que, según refiere, «no me sacaban del agujero». A raíz de una operación de rinoplastia realizada hace un año, de resultado insatisfactorio, ingresó por estado depresivo protagonizando durante el ingreso múltiples alteraciones conductuales que incluyeron fugas, consumo de drogas y peleas con profesionales y residentes. Al alta recibe el diagnostico de Trastorno Limite de la Personalidad y trastorno obsesivo compulsivo y es derivada para atención en hospital de día.

\section{Antecedentes familiares}

Padre con demencia por enfermedad vascular en etapas iniciales.

Madre diagnosticada de trastorno ansioso depresivo y consumo perjudicial de alcohol.

Hermano mediano con posible Trastorno Bipolar.

\section{Situación basal}

Licenciada en económicas, con pareja desde hace ocho años, vive con sus padres en el domicilio familiar. Ha tenido dos trabajos como consultora inmobiliaria de pocos meses de duración, de los que fue despedida. Actualmente está en paro.

\section{Biografía}

La paciente es la menor de tres hermanos, de 39 y 38 años de edad. Su padre, jubilado en la actualidad, trabajaba como director de una promotora inmobiliaria. Su madre regentaba una tienda de arte. La familia refiere un desarrollo sin alteraciones. La madre comenta "fue una niña que llegó por sorpresa, y tal vez nos pilló algo mayores, de pequeña se pasaba el tiempo con la cocinera y con una chica que la cuidaba. Temo no haberle dado demasiado cariño».

La familia es económicamente solvente y todos los hermanos estudian en colegios privados de élite. RB era una niña inquieta, charlatana, con una actividad motora excesiva y caprichosa; comenta al respecto: "siempre me salía con la mía, nunca me negaron nada». Durante la etapa escolar no existen alteraciones el rendimiento académico o la socialización, aunque se recuerda constantemente castigada por ser bastante revoltosa. Durante la adolescencia inicia consumo perjudicial de cannabis 
y alcohol, la relación con sus padres y hermanos se vuelve conflictiva, protagonizando peleas y huidas de casa y establece su primera relación de pareja seria, con un chico con el que está cuatro años. "Al salir con el dejé de lado a mis amigas, yo solo hacía lo que el hacía y lo que el quería, pero también le mangoneaba, nos peleábamos mucho. Con el además empecé a consumir...». Inicia estudios universitarios de económicas en una universidad privada, que completa con un rendimiento adecuado pero a los que la paciente quita mérito «aprobaba todos los exámenes copiando, con chuletas o con pinganillo». Inicia en los primero años de universidad una relación con su actual pareja, con la que lleva casi nueve años «Empezamos a salir porque era el mejor amigo de mi novio y al final ellos se enfadaron por mi.»En estos años, la relación sufre múltiples altibajos con infidelidades, separaciones y peleas que en ocasiones llegan a la agresión verbal y física. Tras terminar estudios universitarios empieza a trabajar en una inmobiliaria por recomendación de un amigo de su padre, pero pierde el trabajo a los pocos meses «creo que los compañeros influyeron en esto porque me veían con demasiado entusiasmo, creo que creyeron que iba de trepa y al final fueron a por mi.». En esa época comienza consumo de cocaína, alteraciones ansioso depresivas y manifiesta síntomas disfóricos en relación con su cuerpo, especialmente su nariz, consultando a multitud de profesionales para intentar corregir el defecto. Consigue otro trabajo por recomendación pero lo pierde de nuevo a los pocos meses sin saber precisar motivos. Recuerda una ocasión en la que saliendo con sus compañeros de trabajo se emborracha y protagoniza una pelea con un policía, pero no sabe hasta que punto este episodio pudo influir en su despido. Tras la operación estética de nariz, pagada por su novio y a los que los padres se niegan, manifiesta intenso malestar con los resultados y retoma tratamiento psicológico.

\section{Enfermedad actual}

Destaca un comportamiento multiimpulsivo, que se inicia durante la adolescencia y se mantiene con carácter grave hasta el momento de la evaluación. La paciente se muestra incapaz de controlar el consumo de tóxicos (cocaína principalmente) y alcohol y, durante los episodios de intoxicación, frecuentemente conduce en estado de embriaguez, tiene peleas, se va a casa de personas desconocidas o desaparece durante varios días sin establecer contacto con su familia. Refiere asimismo excesivos gastos y una conducta sexual promiscua y de riesgo.

Hipereractiva emocionalmente, experimenta episodios de intensa disforia y tristeza que alternan con momentos de euforia que duran horas o minutos. Con las personas más cercanas muestra un comportamiento imprevisible y voluble, con frecuentes episodios de ira en forma de agresiones verbales y físicas. Se muestra especialmente dura con su madre, hacia la que alterna sentimientos ambivalentes de compasión y desprecio. La relación con su pareja, altamente conflictiva (infidelidad, amenazas, agresiones, insultos), le resulta poco satisfactoria pero se siente incapaz de ponerle fin por miedo a sentirse perdida, desvalida y «acabar mal». Lo describe bien como «un enfermo, un loco que va a acabar conmigo» bien como «la única persona que está ahí siempre y que me quiere». Tiene además relaciones inestables pero de alta intensidad emocional con chicos con los que se ve a espaldas de su pareja. Mantiene amigas de la infancia que sirven de apoyo con las que protagoniza frecuentes peleas y reconciliaciones pero reconoce que frecuentemente se aprovecha de ellas para conseguir que justifiquen o escondan los episodios de descontrol o infidelidad; los sentimientos hacia ellas son igualmente variables. A pesar de las frecuentes muestras de mal genio, puede mostrarse excesivamente influenciable y pasiva «una amiga me propuso robar bolsos en el corte inglés y yo como vi que era fácil y ella me lo decía lo hice...». Suspicaz con las personas desconocidas, se siente diana de burlas referidas a su aspecto físico, llegando a afirmar que escucha como las personas la insultan por la por la calle «me llaman fea y me dicen que parezco un mono" Al hablar de si misma muestra frecuentes auto descalificaciones, se siente inmensamente inferior a sus hermanos «que 
son tan perfectitos» e incapaz de asumir ninguna responsabilidad. No tiene una idea clara de si misma, de lo que puede ser y valer, ni siquiera de las cosas que le gustan «Elegí la carrera porque me lo dijo mi padre, no veo a que me podría dedicar, creo que no se como soy como debería ser». Siente que si no tuviera el apoyo estable de su pareja y padres se disolvería. Aunque se muestra en ocasiones dura y mezquina con los miembros de su familia, llora frecuentemente pensando en la posibilidad de que sus padres falten y pueda quedarse sola. Manifiesta una preocupación excesiva e irracional por un defecto físico menor (desviación nasal tras operación estética), acompañada de conductas de comprobación (mirarse al espejo, sacarse fotos, preguntar) que duran horas y suponen un malestar intenso y abandono de algunas actividades. La paciente reconoce solo ocasionalmente que puede estar magnificando la importancia de este defecto. Estas conductas de malestar hacia el defecto y comprobación se hacen mas frecuentes en las etapas de mayor estabilización anímica y conductual, aparecen de forma episódica permaneciendo días con distinta intensidad y remitiendo parcialmente de forma espontanea.

\section{Procedimiento de evaluación}

La evaluación es multidisciplinar, en el contexto de unidad especializada, llevada a cabo por psiquiatra, psicólogo clínico, enfermero especialista y terapeuta ocupacional. El proceso de evaluación se realiza a través de entrevistas clínicas estructuradas SCID I Y II (First 1999; First et al 1999) y semisestructuradas diseñadas ad hoc, y se complementa con test psicométricos (Inventario Clínico Multiaxial de Millon (MCMI II, Millon 2004) Inventario de depresión de Beck (BDI, BeckSteer, y Brown, 2006), Cuestionario de Ansiedad Rasgo y Estado (STAI Spielberger, Gorsuch, y Lushene, 2011). Durante el periodo de evaluación se valora, además, la adecuación de la paciente para iniciar tratamiento en régimen de estancia completa (16 horas semanales). La evaluación multidisciplinar incluye psicopatología, salud física, hábitos de vida, rasgos de personalidad, habilidades de afrontamiento, conciencia de enfermedad, red de apoyo socioafectivo, motivación al cambio y rol ocupacional.

\section{Diagnostico clínico:}

Eje I: Trastorno dismórfico corporal (F45.2)

Eje II: Trastorno límite de la personalidad (F60.31) (Diagnóstico principal)

Eje III: Sin diagnóstico.

Eje IV: Problemas relativos al grupo primario de apoyo. Problema laboral.

Eje V: EEAG 45

A pesar de un claro déficit de autocuidado y de la repercusión social y laboral de la enfermedad en esta paciente, destacan como puntos fuertes motivación al cambio y conciencia de enfermedad, con atribución de la responsabilidad de cambio en uno mismo. La red social de apoyo es extensa e implicada, y el funcionamiento social no está gravemente alterado.

\section{Tratamiento y resultados}

La paciente se incorpora al tratamiento en régimen de estancia completa, es decir, cuatro días a la semana de 10 a 14 horas. El tratamiento incluye las siguientes terapias grupales: Terapia basada en la mentalización según el modelo de Bateman y Fonagy (2006), entrenamiento en habilidades basado en la Terapia Dialéctico Conductual (Linehan, 1993), terapia ocupacional de tipo orientación vocacional, grupo de hábitos de vida saludable y cuidados de enfermería. Recibe además psicoterapia individual y tratamiento farmacológico. Los objetivos terapéuticos fueron:

1. Reducir las conductas potencialmente perjudiciales para la salud, especialmente las relacionadas con el consumo abusivo de drogas y alcohol.

2. Reducir el tiempo dedicado a conductas de comprobación del defecto físico.

3. Mejorar la mentalización e introspección para disminuir la impulsividad y facilitar la capacidad de autoregulación. 
4. Adquirir habilidades de identificación y manejo de emociones y tolerancia al malestar. Manejo de la ira.

5. Desarrollo de habilidades de comunicación y relación interpersonal, especialmente con pareja y familia.

6. Establecimiento de un plan de vida $\mathbf{y}$ futuro.

El tratamiento en estancia completa se alarga durante 6 meses. Al final de este periodo la impulsividad se reduce notablemente, manteniéndose la paciente abstinente total a sustancias durante los dos últimos meses de tratamiento. La preocupación por el defecto físico se reduce en intensidad, siendo los episodios menos frecuentes y duraderos y causando menor interferencia. Muestra mayor autoconciencia y autoconocimiento y es capaz de poner en marcha estrategias útiles de autocontrol (por ejemplo, hacer una lista de pros y contras antes de tomar una decisión impulsiva, llamar a alguien de confianza en momentos de crisis). Las manifestaciones de hostilidad e ira siguen siendo frecuentes, pero se reduce el grado de violencia y van seguidas de comportamientos de reparación apropiados (por ejemplo, pedir disculpas). Se muestra, en ocasiones, capaz de parar la escalada de ira con estrategias autogeneradas (por ejemplo, abandonado la estancia). La paciente muestra un estilo de comunicación más asertivo, especialmente con su madre. Durante el tratamiento inicia estudios de trabajo social, abandona el hogar familiar para vivir con su pareja y se orienta laboralmente al mundo de las ONGs. El seguimiento consiste en psicoterapia individual semanal de un año de duración, junto con tratamiento farmacológico, centrada en reforzar lo aprendido y mejorar el control de la ira por medio del uso de la empatía. Se trabajan además los episodios de ideación paranoide que vuelven a aparecer cuando la paciente se reincorpora al mundo laboral.

\section{Referencias}

American Psychiatric Association APA (2000). Diagnostic and Statistical Manual of Mental Disorders: DSM-IV-TR :Text Revision. (2000). Washington, DC, EE.UU.: Autor.

Bateman, A. y Fonagy, P. (2006). Mentalizationbased Treatment for Borderline Personality Disorder: A Practical Guide. Oxford: Oxford University Press.

Beck, A. T., Steer, R. A. y Brown, G. K. (1996). Inventario de Depresión de Beck BDI-II (2. ${ }^{\mathrm{a}}$ Ed.) [BDI-II Beck Depression Inventory]. Barcelona, España: Paidos Iberica.

First, M. B. (1999). SCID II: Entrevista clínica estructurada para los trastornos de la personalidad del eje II del DSM-IV. Cuestionario de personalidad [Structured Clinical Interview for DSM-IV: Axis II, Personality Disorders, SCID-II]. Barcelona, España: Masson.

First, M. B., Gibbon, M. y Spitzer, R. L. (1999). SCID-I, versión clínica, entrevista clínica estructurada para los trastornos del eje I del DSM-IV [Structured Clinical Interview for DSM-IV Axis I Disorders (SCID-I), Clinician Version]. Barcelona, España: Masson.

Gunderson, J. G. y Links, P. S. (2009). Trastorno límite de la personalidad: guía clínica [Borderline Personality Disorder: A Clinical Guide]. Barcelona, España: Aula Médica.

Linehan, M. (1993). Skills Training Manual for Treating Borderline Personality Disorder. New York: Guilford.

Millon, T. (2004). MCMI-II: Inventario Clínico Multiaxial de Millon-II [Millon Clinical Multiaxial Inventory II (MCMI-II)]. Barcelona, España: TEA.

Spielberger, C. D., Gorsuch, R. L. y Lushene, R. E. (2011). STAI, Cuestionario de Ansiedad EstadoRasgo [State Trait Anxiety Inventory (STAI)]. Barcelona, España: TEA. 
